\title{
Aspectos epidemiológicos da leishmaniose tegumentar americana no município de U batuba, litoral de São Paulo, Brasil, 1993-2003
}

\author{
Epidemiology of American tegumentar leishmaniasis in the municipality of \\ U batuba, N orth coastal area of the state of São Paulo, Brazil, 1993-2003
}

Secretaria de Estado da Saúde de São Paulo Superintendência de Controle de Endemias (Sucen), Taubaté

\begin{abstract}
A leishmaniose tegumentar americana (LTA) é uma doença infecciosa, causada por protozoários do gênero leishmania, transmitida por diferentes espécies de flebotomíneo, que acomete pele e mucosas. E considerada primariamente como zoonose de animais silvestres, e o homem secundariamente.
\end{abstract}

No Brasil, os principais agentes etiológicos da LTA são: Leishmania (L.) amazonensis, Leishmania (V.) guaianensis e Leishmania (V.) brasiliensis, sendo esta responsável pela forma muco-cutânea no Estado de São Paulo. Os reservatórios variam conforme a espécie de leishmania, tendo os principais hospedeiros naturais a preguiça (Choloepus didactilus), o tamanduá (Tamandua Tetradactyla), marsupiais e roedores. É freqüente o encontro de várias espécies domésticas como o cão, eqüinos, mulas, roedores domésticos ou sinantrópicos albergando a Leishmania (V.) brasiliensis.

Os vetores da LTA, que apresentam importância epidemiológica variável de acordo com sua localização geográfica, têm período de vida relativamente curto, de duas a quatro semanas. Estudos desenvolvidos em São Paulo demonstraram a existência de cinco espécies vetoras potenciais: Lutzomyia whitmani, L. migonei, L. pessoai, L. fischeri e L. intermedia sensu lato. Atribui-se a esta última o papel principal na transmissão da LTA no Estado, devido a sua dominância em relação às outras espécies, comportamento antropofílico e domiciliar, e encontro de infecção natural por flagelados.

A transmissão ocorre pela picada do flebotomíneo infectado, com período de incubação no homem em média de dois meses, variando de algumas semanas a dois anos. A manifestação clínica pode variar desde uma simples lesão cutânea até lesões de mucosa, causando mutilações severas e permanentes.

A LTA apresenta-se em fase de expansão geográfica, observando-se nas últimas décadas mudança no comportamento, coexistindo um duplo perfil epidemiológico, expresso pela manutenção de casos oriundos dos focos antigos ou áreas próximas a eles, e pelo aparecimento de surtos epidêmicos, associados a fatores decorrentes de processos migratórios de população, bem como crescimento e urbanização desordenados em áre- as rurais onde existem o ciclo zoonótico e mudanças ambientais produzidas pelo homem.

No Brasil, no período de 1985 a 2001, observou-se uma tendência ao crescimento da endemia, com registro de autoctonia em todos os Estados. A região Nordeste vem contribuindo com maior número de casos e a região Norte com os coeficientes mais elevados.

No Estado de São Paulo, o padrão de transmissão da LTA vem se alterando nos últimos anos, ocorrendo aumento da incidência e expansão geográfica das áreas; na década de 90, os anos de 1993, 1994 e 1995 apresentaram os maiores registro de casos.

A LTA na região do Litoral Norte apresentava casos esporádicos até 1992, notando-se nos anos seguintes elevação da incidência.

A partir de 1978, a LTA passou a fazer parte das doenças de notificação compulsória no Estado, e as atividades para o controle da doença, seguindo as normas do Manual de Vigilância Epidemiológica Normas e Instruções 1978, atualizado em 1995.

Os casos são diagnosticados e notificados pelas Unidades Básicas de Saúde dos municípios, os exames laboratoriais realizados pelo Instituto Adolfo Lutz e o levantamento entomológico, bem como o controle vetorial pela Superintendência de Controle de Endemias, cujas atividades são desencadeadas quando há evidencia de transmissão autóctone em ambiente domiciliar, após ocorrência do segundo caso autóctone num período de seis meses, no mesmo local provável de infecção.

\section{Caracterização do município}

Localizado a $240 \mathrm{Km}$ de São Paulo, entre os paralelos $23^{\circ} 26^{\prime} 09^{\prime}$ 'S e $45^{\circ} 21^{\prime} 28^{\prime \prime} \mathrm{W}$, ocupa uma área de 682 $\mathrm{Km}^{2}$, com altitude de $20 \mathrm{~m}$. Apresenta extensa área coberta pela Mata Atlântica ainda preservada. O clima é tropical úmido, com temperatura mínima de $18^{\circ} \mathrm{C}$ e máxima de $40^{\circ} \mathrm{C}$. Faz divisa ao norte com Paraty (RJ), ao sul com Caraguatatuba (SP) e a oeste com o Vale do Paraíba. A extensão costeira é de aproximadamente 90 
Km. Sua população de 68.787 hab. pode chegar a mais de 300.000 na alta temporada, no verão.

\section{RESU LTAD O S}

No período compreendido entre 1993 e novembro de 2003, foram notificados 122 casos autóctones de LTA no município de Ubatuba. O bairro Camburi apresentou maior número de casos $(31,2 \%)$, com maior incidência nos anos de 1993 e 1994, seguido por Ubatumirim (14,8\%) e Almada (13,9\%), ambos com elevação em 2003 (Tabela). A grande maioria apresentou como local provável de infecção o mesmo da residência, situada sempre próxima ou dentro da mata.

O coeficiente médio de incidência por 100.000 habitantes foi 17,8, com os maiores registros nos anos de 1993, 1994 e 2003 (Figura).

Em relação à distribuição por sexo e faixa etária, constatou-se que $60,6 \%$ dos casos de LTA ocorreram no masculino e $39,4 \%$ no feminino, com ocorrência em todas as faixas, e predomínio entre um e nove anos $(22,1 \%)$ e 20 a 49 anos $(46,5 \%)$.

Quanto à ocupação profissional, 39\% dos casos ocorreram entre menores e estudantes, $16 \%$ atividades domésticas, 6,5\% lavradores e pescadores, e 38,5\% outros.

Em relação à forma clínica, apenas um caso apresentou lesão em mucosa, o restante foi cutânea; houve registro de duas recidivas, no ano de 1994 e 1997.

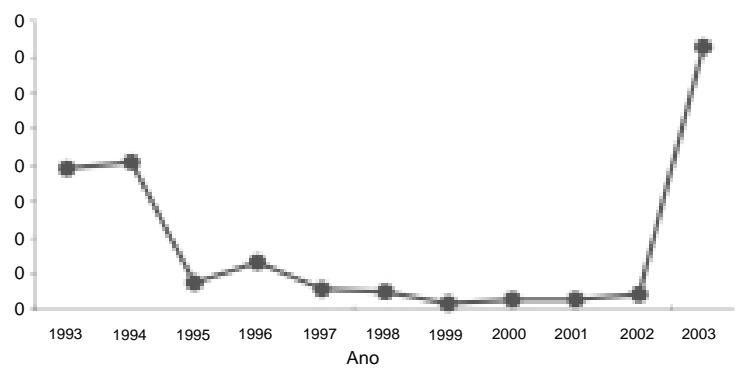

Figura 1 - Incidência de LTA, no município de U batuba, SP, segundo ano de notificação.
As pesquisas entomológicas revelaram predomínio de flebotomíneo da espécie Lutzomyia intermedia, registrando presença no intra e peridomicílio.

A busca ativa foi realizada em todos casos notificados, aplicação de inseticida nos domicílios e peri domicílios ocorreu sempre que a análise da situação epidemiológica indicava a ocorrência de mais de um caso na área, com início de lesão em menos de seis meses.

\section{DISC USSÃO}

No período de 1995 a 2002 (oito anos), foram observadas as menores incidências da doença. Valores mais elevados foram registrados nos anos de 1993 e 2003, sugerindo assim comportamento cíclico da doença.

A presença de casos em todas as faixas etárias e ambos os sexos indica que a transmissão está ocorrendo no ambiente peri ou intradomiciliar .

O registro elevado de $L$. intermedia no intradomicílio sugere ser esta a espécie implicada na transmissão da LTA em Ubatuba.

Comparada com as anteriores, a incidência de 72,74 em 2003 caracteriza este como ano epidêmico. É necessária a elaboração do diagrama de controle para melhor acompanhamento da situação epidemiológica.

A expansão da área de transmissão da LTA, observada em 2003, pode ser explicada pelo crescimento desordenado na ocupação da Mata Atlântica.

Considerando a situação apresentada, evidenciouse a necessidade do aprimoramento nas estratégias de vigilância e controle da LTA, não só em Ubatuba como em todo Litoral Norte, bem como o acompanhamento da ocupação ambiental, reciclagem da capacitação dos profissionais de saúde na rede básica, para diagnóstico e notificação precoce e das ações educativas. Ressalta-se a importância de desenvolver estudos dos reservatórios silvestres e domésticos da LTA.

Tabela - Casos de LTA no município de Ubatuba, SP, segundo local provável de infecção 1993 a 2003.

\begin{tabular}{|c|c|c|c|c|c|c|c|c|c|c|c|c|}
\hline Local Prov. de Infec. & 1993 & 1994 & 1995 & 1996 & 1997 & 1998 & 1999 & 2000 & 2001 & 2002 & 2003* & Total \\
\hline $\begin{array}{l}\text { Camburi } \\
\text { U batumirim } \\
\text { Almada } \\
\text { Picinguaba } \\
\text { Sumidouro } \\
\text { Estaleiro } \\
\text { Ipiranguinha } \\
\text { Itamambuca } \\
\text { Bonete } \\
\text { Corcovado } \\
\text { Eestufa II } \\
\text { Horto } \\
\text { Ignorado } \\
\text { Taquaral } \\
\text { Estufa I } \\
\text { Maranduba } \\
\text { Pedreira } \\
\text { Perequê Açu } \\
\text { Praia do Félix } \\
\text { Promirim } \\
\text { Rio Escuro } \\
\text { Sesmarias }\end{array}$ & $\begin{array}{r}17 \\
1\end{array}$ & $\begin{array}{r}13 \\
4 \\
1 \\
3\end{array}$ & 3 & 2 & 1 & 1 & 1 & $\begin{array}{l}1 \\
1\end{array}$ & $\begin{array}{l}1 \\
1\end{array}$ & 1 & $\begin{array}{r}2 \\
11 \\
15 \\
1 \\
6 \\
5 \\
4 \\
1 \\
1 \\
\\
2 \\
2 \\
\\
1 \\
\\
1 \\
1\end{array}$ & $\begin{array}{c}38(31,2) \\
18(14,8) \\
17(13,9) \\
8(6,6) \\
6(4,9) \\
5(4,2) \\
5(4,2) \\
5(4,2) \\
2(1,6) \\
2(1,6) \\
2(1,6) \\
2(1,6) \\
2(1,6) \\
2(1,6) \\
1(0,8) \\
1(0,8) \\
1(0,8) \\
1(0,8) \\
1(0,8) \\
1(0,8) \\
1(0,8) \\
1(0,8)\end{array}$ \\
\hline Total & $22(18,0)$ & $22(18,0)$ & $4(3,3)$ & $7(5,7)$ & $3(2,5)$ & $3(2,5)$ & $1(0,8)$ & $2(1,6)$ & $2(1,6)$ & $3(2,5)$ & $53(43,5)$ & $122(100,0)$ \\
\hline
\end{tabular}

Fonte: SU CEN -Taubaté/N RS-Caraguatatuba-DIRXXI. *Dados até 31/11/2003. 